\title{
Actinomyces nasicola sp. nov., isolated from a human nose
}

\author{
Correspondence \\ Val Hall \\ hallv@cardiff.ac.uk
}

\author{
Val Hall, ${ }^{1}$ Matthew D. Collins, ${ }^{2}$ Paul A. Lawson, ${ }^{2}$ Enevold Falsen ${ }^{3}$ \\ and Brian I. Duerden ${ }^{1}$ \\ ${ }^{1}$ Anaerobe Reference Unit, Public Health Laboratory Service, University Hospital of Wales, \\ Cardiff, UK \\ ${ }^{2}$ School of Food Biosciences, University of Reading, Reading, UK \\ ${ }^{3}$ Culture Collection, Department of Clinical Bacteriology, University of Göteborg, Göteborg, \\ Sweden
}

\begin{abstract}
A previously undescribed facultatively anaerobic, catalase-negative, Actinomyces-like bacterium was isolated from the nose of a human. On the basis of its cellular morphology and the results of biochemical testing, the micro-organism was tentatively identified as a member of the genus Actinomyces, but it did not correspond to any currently recognized species. Comparative 16S rRNA gene sequencing studies showed the bacterium to be a hitherto unknown subline within the genus Actinomyces, displaying sequence divergence values of more than $6 \%$ with respect to recognized species of the genus. On the basis of biochemical, molecular chemical and molecular phylogenetic evidence, it is proposed that the unknown organism, strain R2014 $\left(=\right.$ CCUG $46092^{\top}=$ CIP $\left.107668^{\top}\right)$, be classified as the type strain of a novel species, Actinomyces nasicola sp. nov.
\end{abstract}

In recent years, the genus Actinomyces has undergone considerable expansion. In the 2nd edition of The Prokaryotes, only 13 species were listed in the genus (Schaal, 1992). However, in the past decade, the genus has increased dramatically in size and at the time of writing comprises 28 species. The vast majority of these new additions to the genus have originated from human clinical specimens, where they occur as mucosal contaminants, whilst some others possibly represent unknown opportunistic pathogens (e.g. Collins et al., 2000; Funke et al., 1994, 1997; Hall et al., 2002; Lawson et al., 2001; Nikolaitchouk et al., 2000; Pascual Ramos et al., 1997; Wüst et al., 1995). Despite this rapid increase in the number of recognized Actinomyces species, it is clear that much novel diversity remains to be discovered, particularly from human sources (Hall et al., 1999, 2001). For example, Hall et al. (2001), using amplified $16 \mathrm{~S}$ rDNA restriction analysis to identify clinical Actinomyces isolates, reported that many of the organisms exhibited genetic profiles that did not correspond to recognized species, raising the possibility that much novel diversity remains to be elucidated from humans. In the course of an ongoing study of taxonomically problematic actinobacteria, we have characterized an unknown catalasenegative, facultatively anaerobic, Actinomyces-like microorganism from the nose of a patient. On the basis of the results of a polyphasic taxonomic study, we describe yet

The GenBank accession number for the $16 \mathrm{~S}$ rRNA sequence of CCUG $46092^{\top}$ is AJ508455. another novel species of the genus Actinomyces, Actinomyces nasicola sp. nov.

The bacterial isolate $\mathrm{R} 2014^{\mathrm{T}}$ was referred to the Anaerobe Reference Unit, PHLS, University Hospital of Wales, for identification. The strain was recovered from an 81-year-old male patient admitted for routine nasal polypectomy. Pus was noted in one antrum and was aspirated. This showed numerous polymorphs and branching Gram-positive, diphtheroid-shaped organisms from which strain $\mathrm{R} 2014^{\mathrm{T}}$ was isolated. The isolate was characterized biochemically by using both conventional tests (Phillips, 1976) and the commercially available API Rapid ID 32A, API Rapid ID 32Strep and API ZYM systems according to the manufacturer's instructions (API bioMérieux). Long-chain cellular fatty acids were analysed as described by Kämpfer \& Kroppenstedt (1996). Quinones were analysed as described by Collins (1994). The $\mathrm{G}+\mathrm{C}$ content (mol\%) of the DNA was determined by HPLC according to Mesbah et al. (1989). Amplified 16S rDNA restriction analyses were performed using HaeIII and HpaII, as described previously (Hall et al., 1999). The 16S rRNA gene of the isolate was amplified by a PCR and sequenced directly using a Taq Dye-Deoxy terminator cycle sequencing kit (Applied Biosystems) and an automatic DNA sequencer (model 373A; Applied Biosystems). The closest known relatives of the novel isolate were determined by performing GenBank/EMBL/ DDBJ database searches. These sequences and those of other known related strains were retrieved from GenBank/ 
EMBL/DDBJ and aligned with the newly determined sequence using the program DNATools (Rasmussen, 1995). The resulting multiple sequence alignment was corrected manually using the program GeneDoc (Nicholas et al., 1997) and a distance matrix was calculated using the program DNADIST (using the Kimura-2 correction parameter) (Felsenstein, 1989). A phylogenetic tree was constructed, according to the neighbour-joining method, with the program NEIGHBOR (Felsenstein, 1989). The stability of the groupings was estimated by bootstrap analysis (500 replications) using the programs DNABOOT, DNADIST, NEIGHBOR and CONSENSE (Felsenstein, 1989). Maximum-parsimony analysis was also performed (Felsenstein, 1989).

The unidentified micro-organism from antral washout consisted of Gram-positive, short, diphtheroid-shaped rods; some branching and coccoid forms were observed. It was non-acid-fast and non-spore-forming. The micro-organism was facultatively anaerobic, but grew better under anaerobic conditions. Acid was formed from fructose and cellobiose but not from amygdalin, arabinose, glucose, lactose, mannitol, mannose, raffinose, ribose, salicin, sucrose, trehalose or xylose in conventional tests. The end-products of glucose metabolism were acetic, lactic and succinic acids. The organism failed to hydrolyse aesculin, gelatin and starch, did not produce indole and was lecithinase-, lipaseand urease-negative. In tests using the API Rapid ID $32 \mathrm{~A}$ kit, the isolate displayed activity for alanine arylamidase, arginine arylamidase, $\beta$-galactosidase, $\alpha$-glucosidase, $\beta$-glucosidase, glycine arylamidase, histidine arylamidase, proline arylamidase, leucine arylamidase, $\mathrm{N}$ acetyl- $\beta$-glucosaminidase, phenylalanine arylamidase, serine arylamidase and tyrosine arylamidase. Activity for arginine dihydrolase, pyroglutamic acid arylamidase and glutamyl glutamic acid arylamidase was either weak or absent. All other tests in the API Rapid ID 32A kit gave negative results. With the API Rapid ID 32Strep system, the isolate showed activity for alanine-phenylalanine-proline arylamidase, $\beta$-galactosidase, $\beta$-glucosidase and $N$-acetyl- $\beta$-glucosaminidase but gave negative reactions for all of the other tests. With the API ZYM test kit, activity for $\beta$-galactosidase, $\alpha$-glucosidase, leucine arylamidase, $N$-acetyl- $\beta$-glucosaminidase and valine arylamidase was detected but all other enzyme tests were negative.

The long-chain cellular fatty acids of the organism consisted of a complex mixture of straight-chain saturated, monounsaturated, iso-methyl-branched and anteiso-methyl-branched types, with anteiso-C15 (13\%), C16:0 (29\%), C18:0 $(11 \%)$ and $\mathrm{C} 18: 1 \omega 9 c(26 \%)$ as the major acids. Other acids were present in relatively small amounts [iso-C14 $(1.5 \%)$, $\mathrm{C} 14: 0(7 \cdot 5 \%)$, iso-C15 (3\%), C15:0 (1\%), iso-C16:0 (2\%), C16:1 (0.5\%), iso-C17 (1.5\%), anteiso-C17 (1.5\%) and C17:0 (1\%)]. The organism contained menaquinones as the sole respiratory lipoquinones, with MK-9 (90\%) as the major component, together with small amounts of MK-10 (10\%). The cellular morphology and biochemical reactions of the micro-organism were consistent with its tentative assignment to the genus Actinomyces, but it did not appear to correspond to any recognized species of this genus. To clarify the genetic relatedness of the unidentified micro-organism to Actinomyces species, amplified $16 \mathrm{~S}$ rDNA restriction analyses were performed. The unknown micro-organism produced a unique $16 \mathrm{~S} \mathrm{rDNA}$ restriction pattern with HaeIII and HpaII (profile 072/058) that was distinct from the profiles derived from analysis of over 400 Actinomyces strains (Hall et al., 2001). To investigate the phylogenetic relationships of the unknown micro-organism, its almost complete 16S rRNA gene sequence (>1400 nt) was determined. Sequence database searches confirmed that the unknown isolate was most closely related to species of the genus Actinomyces. The highest sequence relatedness was shown to Actinomyces hordeovulneris CIP $103149^{\mathrm{T}}(93 \cdot 4 \%)$, Actinomyces canis CCUG $41706^{\mathrm{T}}(91 \cdot 8 \%)$ and Actinomyces marimammalium CCUG $41710^{\mathrm{T}}(91 \cdot 4 \%)$, with other Actinomyces species displaying lower levels of relatedness ( $<91 \%$; data not shown). Neighbour-joining treeing analysis further demonstrated the distinctiveness of the clinical isolate, with the organism forming a distinct subline, clustering with A. hordeovulneris CIP $103149^{\mathrm{T}}$ (Fig. 1). Parsimony analysis confirmed the affinity between the unidentified bacterium and A. hordeovulneris.

It is evident from the findings presented that the unidentified facultatively anaerobic, catalase-negative, rod-shaped micro-organism represents another hitherto unknown Actinomyces species from clinical sources. Comparative $16 \mathrm{~S}$ rRNA gene sequencing shows that the unknown isolate forms a distinct subline within the genus Actinomyces and displays a specific affinity with A. hordeovulneris CIP $103149^{\mathrm{T}}$, a species associated with canine actinomycosis (Buchanan et al., 1984). Bootstrap resampling showed that the clustering of the unknown bacterium with A. hordeovulneris was statistically significant (91\% bootstrap value based on 500 tree replications). However, a 16S rDNA sequence divergence of approximately $6.6 \%$ between the unidentified isolate and the type strain of A. hordeovulneris showed that this association was not particularly close. Although there is no precise correlation between percentage $16 \mathrm{~S}$ rDNA sequence divergence values and species delineation, it is now generally accepted that micro-organisms displaying values of $3 \%$ or more do not belong to the same species (Stackebrandt \& Goebel, 1994). The observed $>6 \%$ sequence divergence between the unidentified clinical isolate and A. hordeovulneris therefore demonstrates clearly that these micro-organisms represent quite different species. The next nearest phylogenetic relative of the unknown clinical bacterium corresponds to A. marimammalium. However, sequence divergence considerations and treeing analysis indicate that this association is relatively loose. Support for the separateness of the unknown bacterium also comes from phenotypic evidence. In particular, the biochemical profile of the human clinical isolate serves to distinguish it from all currently recognized Actinomyces species. The unidentified isolate can be readily 


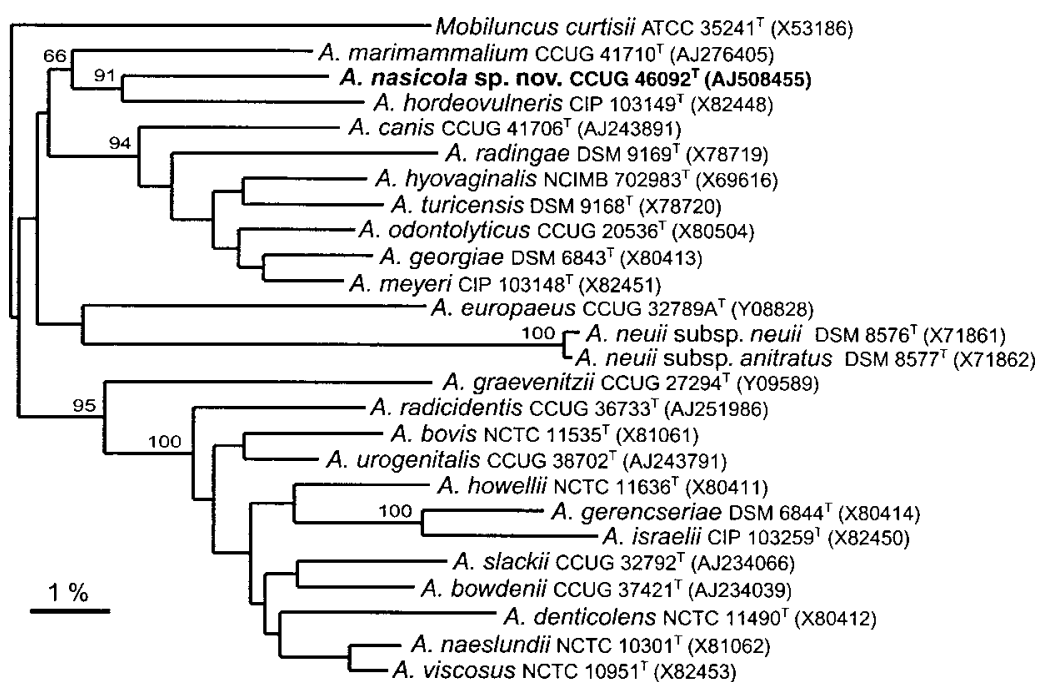

Fig. 1. Tree showing the phylogenetic relationships of Actinomyces nasicola sp. nov. CCUG $46092^{\top}$ and its nearest relatives in the genus Actinomyces. The tree, constructed using the neighbour-joining method, was based on a comparison of approx. 1327 nucleotides. Bootstrap values, expressed as percentages of 500 replications, are given at branching points. Bar, $1 \%$.

distinguished from its closest relative, A. hordeovulneris, by several biochemical traits. In particular, the human clinical isolate ferments a much narrower range of carbohydrates than $A$. hordeovulneris. In addition, the dog pathogen A. hordeovulneris can be differentiated from the human clinical isolate by its positive catalase, $\alpha$-galactosidase and glycine-tryptophan arylamidase reactions, the unknown clinical bacterium showing the opposite response. Tests (in the commercially available API Rapid ID 32Strep system) that are useful in distinguishing the novel bacterium from $A$. hordeovulneris and its next nearest phylogenetic relative, A. marimammalium, are shown in Table 1.

On the basis of the distinct phenotypic characteristics of the unidentified rod-shaped bacterium and the molecular chemical and molecular genetic evidence, we consider that this micro-organism warrants classification as a novel

Table 1. Tests that are useful in distinguishing $A$. nasicola sp. nov. from its closest phylogenetic relatives using the API Rapid ID 32Strep system

Strains: 1, A. hordeovulneris CCUG $32937^{\mathrm{T}}$, CCUG 34476 and CCUG 34478; 2, A. marimammalium CCUG $41710^{\mathrm{T}}$ and CCUG 42833; 3, A. nasicola sp. nov. CCUG $46092^{\mathrm{T}}$. +, Positive; - , negative; $\mathrm{V}$, variable.

\begin{tabular}{|lccc|}
\hline Test & $\mathbf{1}$ & $\mathbf{2}$ & $\mathbf{3}$ \\
\hline Acid from: & & & \\
$\quad$ Glycogen & $\mathrm{V}$ & $\mathrm{V}$ & - \\
Lactose & + & $\mathrm{V}$ & - \\
Pullulan & + & - & - \\
Sucrose & + & - & - \\
Production of: & & & \\
$\alpha$-Galactosidase & + & - & - \\
$\beta$-Glucosidase & + & - & + \\
Glycine-tryptophan arylamidase & + & + & - \\
\hline
\end{tabular}

species of the genus Actinomyces, for which the name Actinomyces nasicola sp. nov. is proposed. Although only a single strain of A. nasicola is currently known, we consider that the formal description of this species, together with biochemical and chemical criteria to assist with its identification, will facilitate its recognition in clinical laboratories, thereby permitting the recovery of additional strains of this species and an evaluation of its distribution, clinical prevalence and possible significance.

\section{Description of Actinomyces nasicola sp. nov.}

Actinomyces nasicola (na.si'co.la. L. masc. n. nasus nose; L. masc. suffix -cola inhabitant of; N.L. masc. n. nasicola inhabitant of the nose, referring to the place of isolation of the type strain).

Cells are Gram-positive, short, diphtheroid-shaped rods; some branching and coccoid forms occur. Non-acid-fast and non-spore-forming. After $48 \mathrm{~h}$ anaerobic incubation on fastidious anaerobe agar, colonies are pinpoint, white or grey, opaque, shiny, entire and convex. Facultatively anaerobic; grows in air but grows better under anaerobic conditions. Catalase-negative. Acid is formed from fructose and cellobiose but not from amygdalin, arabinose, glucose, lactose, mannitol, mannose, raffinose, ribose, salicin, sucrose, trehalose or xylose in conventional tests. Acetic, lactic and succinic acids are the end-products of glucose metabolism. Aesculin, gelatin and starch are not hydrolysed. Lecithinase, lipase and urease are not produced. With API systems, acid is not produced from D-arabitol, L-arabinose, cyclodextrin, glycogen, lactose, maltose, mannitol, mannose, melibiose, melezitose, methyl $\beta$-D-glucopyranoside, pullulan, raffinose, ribose, sorbitol, sucrose, tagatose, trehalose or D-xylose. Hippurate is not hydrolysed, indole is not produced and nitrate is not reduced. Activity is detected for alanine arylamidase, alanine-phenylalanine-proline arylamidase, arginine arylamidase, $\beta$-galactosidase, $\alpha$-glucosidase, glycine arylamidase, histidine arylamidase, proline arylamidase, leucine 
arylamidase, $N$-acetyl- $\beta$-glucosaminidase, phenylalanine arylamidase, serine arylamidase, valine arylamidase or tyrosine arylamidase. Activity may or may not be detected for arginine dihydrolase, glutamyl glutamic acid arylamidase, pyroglutamic acid arylamidase and $\beta$-glucosidase. No activity is detected for $\alpha$-arabinosidase, acid phosphatase, alkaline phosphatase, cysteine arylamidase, esterase $\mathrm{C}_{4}$, ester lipase $\mathrm{C}_{8}, \alpha$-fucosidase, $\alpha$-galactosidase, $\beta$-galactosidase- 6 phosphate, glycine-tryptophan arylamidase, glutamic acid decarboxylase, $\beta$-glucuronidase, lipase $\mathrm{C}_{14}, \alpha$-mannosidase, $\beta$-mannosidase, phosphoamidase, pyrrolidonyl arylamidase, chymotrypsin, trypsin or urease. Voges-Proskauernegative. The major respiratory quinone is MK-9. The long-chain cellular fatty acids are of the straight-chain saturated, monounsaturated, iso-methyl-branched and anteiso-methyl-branched types, with anteiso-C15, C16:0, $\mathrm{C} 18: 0$ and $\mathrm{C} 18: 1 \omega 9 \mathrm{c}$ as the major components. The $\mathrm{G}+\mathrm{C}$ content of the DNA of the type strain is $66.5 \mathrm{~mol} \%$.

The type strain, R2014 ${ }^{\mathrm{T}}\left(=\right.$ CCUG $46092^{\mathrm{T}}=$ CIP $\left.107668^{\mathrm{T}}\right)$, was isolated from antrum aspirate. Habitat unknown.

\section{References}

Buchanan, A. M., Scott, J. L., Gerencser, M. A., Beaman, B. L., Jang, S. \& Biberstein, E. L. (1984). Actinomyces hordeovulneris sp. nov., an agent of canine actinomycosis. Int J Syst Bacteriol 34, 439-443.

Collins, M. D. (1994). Isoprenoid quinones. In Chemical Methods in Prokaryotic Systematics, pp. 265-309. Edited by M. Goodfellow \& A. G. O'Donnell. Chichester: Wiley.

Collins, M. D., Hoyles, L., Kalfas, S., Sundquist, G., Monsen, T., Nikolaitchouk, N. \& Falsen, E. (2000). Characterization of Actinomyces isolates from infected root canals of teeth: description of Actinomyces radicidentis sp. nov. J Clin Microbiol 38, 3399-3403.

Felsenstein, J. (1989). PHYLIP - phylogeny inference package (version 3.2). Cladistics 5, 164-166.

Funke, G., Stubbs, S., von Graevenitz, A. \& Collins, M. D. (1994). Assignment of human-derived CDC group 1 coryneform bacteria and CDC group 1-like coryneform bacteria to the genus Actinomyces as Actinomyces neuii subsp. neuii sp. nov., subsp. nov., and Actinomyces neuii subsp. anitratus subsp. nov. Int J Syst Bacteriol 44, 167-171.

Funke, G., Alvarez, N., Pascual, C., Falsen, E., Akervall, E., Sabbe, L., Schouls, L., Weiss, N. \& Collins, M. D. (1997). Actinomyces europaeus sp. nov., isolated from human clinical specimens. Int J Syst Bacteriol 47, 687-692.
Hall, V., O'Neill, G. L., Magee, J. T. \& Duerden, B. I. (1999). Development of amplified 16S ribosomal DNA restriction analysis for identification of Actinomyces species and comparison with pyrolysis-mass spectrometry and conventional biochemical tests. J Clin Microbiol 37, 2255-2261.

Hall, V., Talbot, P. R., Stubbs, S. L. \& Duerden, B. I. (2001). Identification of clinical isolates of Actinomyces species by amplified 16S ribosomal DNA restriction analysis. J Clin Microbiol 39, 3555-3562.

Hall, V., Collins, M. D., Hutson, R., Falsen, E. \& Duerden, B. I. (2002). Actinomyces cardiffensis sp. nov., from human clinical sources. J Clin Microbiol 40, 3427-3431.

Kämpfer, P. \& Kroppenstedt, R. M. (1996). Numerical analysis of fatty acid patterns of coryneform bacteria and related taxa. Can J Microbiol 42, 989-1005.

Lawson, P. A., Nikolaitchouk, N., Falsen, E., Westling, K. \& Collins, M. D. (2001). Actinomyces funkei sp. nov., isolated from human clinical specimens. Int J Syst Evol Microbiol 51, 853-855.

Mesbah, M., Premachandran, U. \& Whitman, W. B. (1989). Precise measurement of the $\mathrm{G}+\mathrm{C}$ content of deoxyribonucleic acid by high-performance liquid chromatography. Int J Syst Bacteriol 39, 159-167.

Nicholas, K. B., Nicholas, H. B., Jr \& Deerfield, D. W. (1997). GeneDoc: analysis and visualisation of genetic variation. $E M B N E W$ News 4, 14.

Nikolaitchouk, N., Hoyles, L., Falsen, E., Grainger, J. M. \& Collins, M. D. (2000). Characterization of Actinomyces isolates from samples from the human urogenital tract: description of Actinomyces urogenitalis sp. nov. Int J Syst Evol Microbiol 50, 1649-1654.

Pascual Ramos, C., Falsen, E., Alvarez, N., Åkervall, E., Sjödén, B. \& Collins, M. D. (1997). Actinomyces graevenitzii sp. nov., isolated from human clinical specimens. Int J Syst Bacteriol 47, 885-888.

Phillips, K. D. (1976). A simple and sensitive technique for determining the fermentation reactions of non-sporing anaerobes. J Appl Bacteriol 41, 325-328.

Rasmussen, S. W. (1995). DNATools, a Software Package for DNA Sequence Analysis. Carlsberg Laboratory, Copenhagen, Denmark.

Schaal, K. P. (1992). The genera Actinomyces, Arcanobacterium, and Rothia. In The Prokaryotes, 2nd edn, vol. 1, pp. 850-905. Edited by A. Balows, H. G. Trüper, M. Dworkin, W. Harder \& K. H. Schleifer. New York: Springer.

Stackebrandt, E. \& Goebel, B. M. (1994). Taxonomic note: a place for DNA-DNA reassociation and 16S rRNA sequence analysis in the present species definition in bacteriology. Int J Syst Bacteriol 44, 846-849.

Wüst, J., Stubbs, S., Weiss, N., Funke, G. \& Collins, M. D. (1995). Assignment of Actinomyces pyogenes-like (CDC coryneform group E) bacteria to the genus Actinomyces as Actinomyces radingae sp. nov. and Actinomyces turicensis sp. nov. Lett Appl Microbiol 20, $76-81$. 